\title{
Steroid Hormones and Homocysteine in the Outcome of Patients With Normal Pressure Hydrocephalus
}

\author{
L. SOSVOROVA ${ }^{1}$, M. MOHAPL ${ }^{2}$, M. HILL ${ }^{1}$, L. STARKA ${ }^{1}$, M. BICIKOVA ${ }^{1}$, J. VITKU $^{1}$, \\ R. KANCEVA ${ }^{1}$, J. BESTAK ${ }^{1}$, R. HAMPL ${ }^{1}$ \\ ${ }^{1}$ Department of Steroids and Proteofactors, Institute of Endocrinology, Prague, Czech Republic, \\ ${ }^{2}$ Department of Neurosurgery, University Military Hospital, Prague, Czech Republic
}

Received May 18, 2015

Accepted June 1, 2015

\begin{abstract}
Summary
Normal pressure hydrocephalus (NPH) is one of a few treatable conditions of cognitive decline affecting predominately elderly people. Treatment, commonly based on the ventriculoperitoneal shunt insertion, leads to a partial or complete correction of patient's state, although its effect does not unfortunately always last. The aim of our study was to observe the changes of homocysteine and selected steroids and neurosteroids and follow-up the patients with respect to the duration of the $\mathrm{NPH}$-related dementia improvement. The cerebrospinal fluid and plasma levels of cortisol, cortisone, dehydroepiandrosterone (DHEA), 7a-hydroxy-DHEA，7ß-hydroxy-DHEA，7-oxo-DHEA， 16a-hydroxy-DHEA (all LC-MS/MS), DHEA-sulphate (DHEAS) (radioimmunoassay) and homocysteine (gas chromatography) were determined in NPH-diagnosed subjects before, during and 6, 12 and 24 months after shunt insertion. The cognitive functions ameliorated after shunt insertion and remain improved within 2 years. Changes in cerebrospinal fluid DHEAS, DHEA and its ratio, cortisone/cortisol and 16a-hydroxy-DHEA and plasma DHEAS, 7 $\beta$-hydroxy-DHEA, cortisone/cortisol and homocysteine were found. Mentioned changes may contribute to the clarification of NPH pathogenesis. Altered neurosteroids levels are possible indicators to be utilized in the follow-up of NPH subjects. Moreover, plasma homocysteine may serve as an early indicator of NPH-related dementia.
\end{abstract}

\section{Key words}

Normal pressure hydrocephalus - Steroids - Neurosteroids • Homocysteine • Dementia

\begin{abstract}
Corresponding author
L. Sosvorova, Department of Steroids and Proteofactors, Institute of Endocrinology, Narodni 8, 11694 Prague, Czech Republic. E-mail: Isosvorova@endo.cz
\end{abstract}

\section{Introduction}

Steroids and especially those acting or directly synthesized in the brain (neuroactive steroids and neurosteroids, respectively) are known to display neuroprotective properties (Wojtal et al. 2006). Their altered levels were found in the majority of neurodegenerative disorders including normal pressure hydrocephalus (NPH) (Luchetti et al. 2011, Giatti et al. 2015, Sosvorova et al. 2015a).

Some neurosteroids appeared to be valuable analytes in the search for the biomarkers of neurodegenerative disorders. Among the most promising ones are dehydroepiandrosterone (DHEA), its metabolites and its sulfate (DHEAS). The main portion of DHEA is synthesized in the adrenals; the rest originates in gonads, adipose tissue and brain. The accumulation of DHEA, its precursors and metabolites in the brain is partly independent of the adrenal and gonadal sources. Therefore, these steroids as well as pregnenolone and its metabolites are termed neurosteroids (Corpechot et al. 1981). The blood-brainbarrier (BBB) is easily penetrable for DHEA but only for minor amounts of DHEAS (Kancheva et al. 2010). Both steroids have a broad range of biological effects including anti-inflammatory, antiglucocorticoid, immunoprotective and neuroprotective ones (Stárka et al. 2014). The levels of DHEA and DHEAS decline 
considerably with age and the reduced levels of the mentioned hormones correlate with several neurodegenerative disorders (Hampl et al. 2003, El Kihel 2012).

DHEA is intensively metabolized in various tissues, including the brain. An important portion of DHEA is transformed to DHEA 7-oxygenated derivatives, specifically $7 \alpha$-hydroxy-DHEA, 7 $\beta$-hydroxy-DHEA and their intermediate, 7-oxoDHEA (Robinzon et al. 2003, Seckl and Walker 2004, Muller et al. 2006). These metabolites, showing similar effects to DHEA, may stay behind its beneficial properties (Morfin and Starka 2001, Kancheva et al. 2010, Ferroud et al. 2012). The 7-oxygenated DHEA metabolites are interconverted via type 1 11 $\beta$-hydroxysteroid dehydrogenase (HSD11B1), which is also responsible for the interconversion of cortisol and cortisone in glucocorticoid responsive tissues including the brain (Seckl and Walker 2004, Muller et al. 2006, Vitku et al. 2014). The concurrent metabolic pathway to 7-hydroxylation is the hydroxylation at carbon 16 leading to $16 \alpha$-hydroxy-DHEA (Hampl et al. 2003). So far, there have been no reports of $16 \alpha$-hydroxy-DHEA in the brain, but it has been identified in the human cerebrospinal fluid (CSF) (Kancheva et al. 2010, Sosvorova et al. 2015b). It was also assumed, that elevated $16 \alpha$-hydroxy-DHEA levels may counteract the benefit properties of 7-oxygenated DHEA metabolites, as well as cortisol occupying the same enzyme (Morfin and Starka 2001).

Cortisol as well as its inactive form cortisone pass through the $\mathrm{BBB}$ to the CSF, where both can be interconverted via HSD11B1 (Guazzo et al. 1996, Sinclair et al. 2010). CSF cortisol is important in the regulation of the inner milieu of brain ventricles. Although this steroid is known mainly as a glucocorticoid, when considering its huge excess over aldosterone, it also competes for mineralocorticoid receptors in the brain (Leenen 2010). Elevated CSF cortisol levels are also known to be associated with several neurodegenerative disorders (Sosvorová et al. 2012, Popp et al. 2015).

The levels of homocysteine, an independent indicator of oxidative stress, are known to be increased in neurodegenerative disorders. Elevated plasma and CSF homocysteine levels were recorded in various type of dementia, Alzheimer's and Parkinson's disease (Seshadri et al. 2002, Bičíková et al. 2004, Isobe et al. 2005). The levels of homocysteine as well as neurosteroids are altered in the majority of neurodegenerative disorders, thus they could serve as disease biomarkers. Recently, the research in this field was expanded also to the NPH, one of the important underdiagnosed neurodegenerative diseases (Sosvorova et al. 2014, 2015a).

Over the years, NPH has been known as a syndrome of treatable gait and dementia disorder. It is one of a few treatable conditions of cognitive decline which affects about $5 \%$ of patients with dementia (Nigim et al. 2014). Despite nearly 5 decades of investigation, the pathophysiology of NPH remains still unclear. It affects predominately elderly people and is characterized by gait disturbance, urinary incontinence and dementia development, which may occur in varying combinations or degrees of each feature (Forner Giner et al. 2014). The various disease presentation and overlap with other neurodegenerative, infectious or urological diseases (Relkin et al. 2005) makes the diagnosis difficult. According to the recent data, the NPH prevalence ranges from 0.2 to $5.9 \%$ and increases with advancing age. However, the majority of patients are either underdiagnosed or misdiagnosed in the clinical practice (Jaraj et al. 2014).

The therapeutic approach for NPH consists of the insertion of ventriculoperitoneal shunt (SHI), draining cerebrospinal fluid to the abdominal cavity (Bergsneider et al. 2005, Reddy et al. 2014), which can lead to a partial or complete correction of patient's state (Rigamonti 2014). However, the SHI's effect is unfortunately not all the time durable. Recent data showed that nearly one half of the primarily shuntresponsive NPH patients eventually developed NPHrelated dementia within approximately 5 years of SHI (Klinge et al. 2012, Poca et al. 2012, Kazui et al. 2013).

Until now, no reliable biomarker to predict NPH outcome after SHI has been found, although an extensive research is in progress (Rigamonti 2014). However, data linked to the pathophysiological changes of homocystein levels as well as altered steroidogenesis are still missing. To fill this gap, we followed the changes of cortisol, cortisone, DHEA, DHEAS, 7 $\alpha$-hydroxy-DHEA, 7 $\beta$-hydroxy-DHEA, 7-oxo-DHEA, $16 \alpha$-hydroxy-DHEA and homocysteine in CSF and plasma in the NPH diagnosed patients before, during and 6, 12 and 24 months after SHI. The aim of our study was to find out laboratory indicators which could serve to predict the patient's prognosis. 


\section{Materials and Methods}

\section{Chemicals and solutions}

Cortisol, cortisone and dehydroepiandrosterone (DHEA) were purchased from Koch-Light Laboratories LTD (Colnbrook, Great Britain); 7 $\alpha$-hydroxy-DHEA, 7 $\beta$-hydroxy-DHEA, 7-oxo-DHEA, 16 $\alpha$-hydroxy-DHEA and D3-DHEA were from Steraloids (Newport, USA). D4-Cortisol was from CDN isotopes (Ponte-Claire, Canada). 2-hydrazinopyridine, ammonium formate, methyl tert-butyl ether, trifluoroacetic acid, homocystine, dithiothreitol, pyridine, p-fluoro-DL-phenylalanine, ethyl chloroformate, isooctane, ethanol, chloroform, sodium chloride, hydrochloric acid and potassium oxalate monohydrate were from Sigma-Aldrich (St. Louis, USA). LC-MS grade methanol and water as well as diethyl ether were from Merck AG (Darmstadt, Germany). The physiological solution was from B-Braun (Melsungen AG, Germany).

\section{Subjects}

The patients' group included 24 subjects aged 65-80 years (13 men, 11 women) with non-obstructive idiopathic NPH diagnosed on the basis of a combination of NMR imaging and a lumbar drainage test (Walchenbach et al. 2002). CSF was collected during a five-day lumbar drainage test (LD). The ventriculoperitoneal shunt was introduced to all of the patients diagnosed with NPH after finishing the LD. CSF and plasma were collected in the first (D1) and fifth day (D5) of LD, as well as 6 (M6), 12 (M12) and 24 months (M24) after SHI. In addition CSF was collected also during the SHI.

In parallel with the plasma and CSF collection, patient's clinical state was recorded. Two patients stopped participation before six months of the follow up due to worsening of their clinical status, not connected with the performed neurosurgical procedure. In two patients a shunt malfunction led to clinical deterioration with recurrence of NPH symptoms, which however improved immediately after shunt revision took place. Four patients died during the second year of the follow up due to another diseases. Gait disturbances were evaluated using videorecording and analysis of gait on $10 \mathrm{~m}$ track. Neuropsychological functions were assessed by testing battery consisting of WMS - Wechsler memory test, CVLT - California Verbal Learning Test, Rey-Osterrieth Complex Figure Test, Cognitive Estimation Test, part of WAIS-R - Wechsler adult intelligence test and Beck Depression Inventory for estimation of depression level - complete analysis is beyond extent of the article - effect of treatment on memory was summarized as "same, improved or worsened".

All surgeries were performed at the Department of Neurosurgery of University Military Hospital Prague. Patients' samples were collected in plastic tubes, subsequently frozen, stored at $-80{ }^{\circ} \mathrm{C}$ and transported to the Institute of Endocrinology. The protocol of the study was approved by the Ethical Committee of the Institute of Endocrinology. Written informed consent was obtained from all participants included in the study.

\section{Steroid and homocysteine analysis}

The CSF and plasma levels of cortisol, cortisone, DHEA, $7 \alpha$-hydroxy-DHEA, 7 $\beta$-hydroxy-DHEA, 7-oxoDHEA and 16 $\alpha$-hydroxy-DHEA were measured by liquid chromatography-tandem mass spectrometry (LC-MS/ MS) method described elsewhere (Sosvorova et al. 2015b). Plasma DHEAS was measured using a DHEAS kit from Immunotech (Beckman Coulter Company, Marseille, France). DHEAS in CSF was determined by radioimmunoassay using a DHEA kit from Immunotech (Beckman Coulter Company, Marseille, France), after removing the unconjugated DHEA by diethyl ether extraction. The antiserum used in the kit cross-reacted with DHEAS by approximately $30 \%$ and the assay was sensitive enough to detect DHEAS in CSF, contrary to DHEAS kit, tailored for the measurement of DHEAS in plasma.

Homocysteine in CSF and plasma was measured by a gas chromatography method with flame ionization detection (GC-FID) as described elsewhere (Hušek et al. 2003, Sosvorova et al. 2014).

\section{Statistical analysis}

The relationships between dependent variables and effect of stage of the experiment were evaluated using repeated measures of the ANOVA model consisting of the following factors: Stage (D1, D5, SHI, M6, M12 and M24) and Subject (explaining inter-individual variability). The ANOVA model was followed by least significant difference (LSD) multiple comparisons. To eliminate skewed data distribution and heteroscedasticity, the original data were transformed by a power transformation to attain Gaussian distribution and constant variance before further processing. Statistical software Statgraphics Centurion, version XV from 
Statpoint Inc. (Herndon, Virginia, USA) was used for data processing.

\section{Results}

All of the participants showed an improvement of at least one of the clinical symptoms followed at the M6 period of examination. The CSF and plasma levels of cortisol, cortisone, DHEA, DHEAS, $7 \alpha$-hydroxy-DHEA, 7 $\beta$-hydroxy-DHEA, 7-oxo-DHEA, 16 $\alpha$-hydroxy-DHEA and homocysteine in individual stages are summarized in Figure 1 and Figure 2.

1) Shunting procedure led to improvement of gait disturbances in 22 of 24 patients, neuropsychological testing results were improved in all 18 patients with preoperative memory impairment and improvement of urinary incontinence were recorded in 6 of 12 patients. In no one of patients the initially memory impairment worsened during 2-year observed period showing no NPH-dementia related changes development.

2) The CSF cortisone levels and cortisone/ cortisol ratio decreased during LD. During SHI, CSF cortisone increased to D1 levels and remains stable within 2 years $(p<0.01)$. Cortisone/cortisol ratio increased during SHI over D1 levels and within 1 year, decreased back to the former levels $(\mathrm{p}<0.01)$.

3) The plasma cortisone/cortisol ratio decreased between 6 and 12 months from SHI and remained stable until M24 $(\mathrm{p}<0.05)$.

4) The CSF DHEA decreased during LD $(p<0.05)$ and during SHI, within 2 years remains stable. The CSF DHEAS was higher before SHI. When comparing M6 and M24, the levels of DHEAS decreased $(p<0.01)$. The ratio DHEAS/DHEA decreased between LD and SHI. Concerning long term after SHI, DHEAS/DHEA decreased between first and second year after SHI $(\mathrm{p}<0.01)$.

5) The plasma levels of DHEAS and homocysteine increased sequentially during the observed period. The highest difference in DHEAS was observed between first and second year after SHI $(p<0.05)$. An increase of plasma homocysteine from D1 was discovered within 1 year and increased within 2 years from SHI $(\mathrm{p}<0.05)$.

6) The levels of CSF 16 $\alpha$-hydroxy-DHEA decreased after SHI; within 2 years, the levels remain stable $(\mathrm{p}<0.01)$.
7) Plasma 7 $\beta$-hydroxy-DHEA increased stepwise between first and second year after SHI $(\mathrm{p}<0.05)$.

8) The differences in CSF cortisol, homocysteine, 7-oxygenated-DHEA metabolites, as well as plasma cortisol, cortisone, DHEA, $7 \alpha$-hydroxy-DHEA, 7-oxo-DHEA and 16 $\alpha$-hydroxy-DHEA did not change significantly within the observed period.

\section{Discussion}

For the first time we measured time changes of above mentioned steroid hormones and homocysteine in CSF and plasma of patients with NPH before and during the two-year period following SHI. We tried to select suitable analytes, which could serve as indicators for the follow-up on the NPH disease progress.

DHEAS, DHEA and its metabolites are known to be altered in neurodegenerative disorders (Brown et al. 2003, Kim et al. 2003, Naylor et al. 2008). Most of the steroid-metabolizing enzymes occurring in adrenals and gonads have also been found in the brain. The brain contains additional steroid metabolizing enzymes including sulfotransferase (low activity) converting DHEA to DHEAS and sulfatase (relatively high activity) hydrolyzing DHEAS to DHEA (Mellon 2003). Both enzymes play an important role in the brain tissues, with respect to the limited ability of DHEAS to pass across the BBB (Hampl et al. 2003). After SHI, we presumed the normalization of DHEAS levels in CSF. The increased CSF levels of DHEAS in patients with NPH before SHI point to increased sulfation, in contrast to Alzheimer's and vascular dementia patients. Another explanation is the disturbance of $\mathrm{BBB}$ as a consequence of enlarged brain ventricle space, resulting in increased permeability of DHEAS across the BBB. The continuous decrease of CSF DHEAS during LD and after SHI reflects the amelioration and normalization of the patient's state. This process may be caused by the reinstatement of brain sulfatase activity or the amelioration of BBB function which limits the DHEAS transport across the BBB. This hypothesis is supported by the plasma DHEAS increase with the highest increase within 1 year from SHI. Therefore, the differences in the DHEA sulfation in the human brain may serve as a diagnostic tool in NPH diagnostics and following therapeutic progress. 

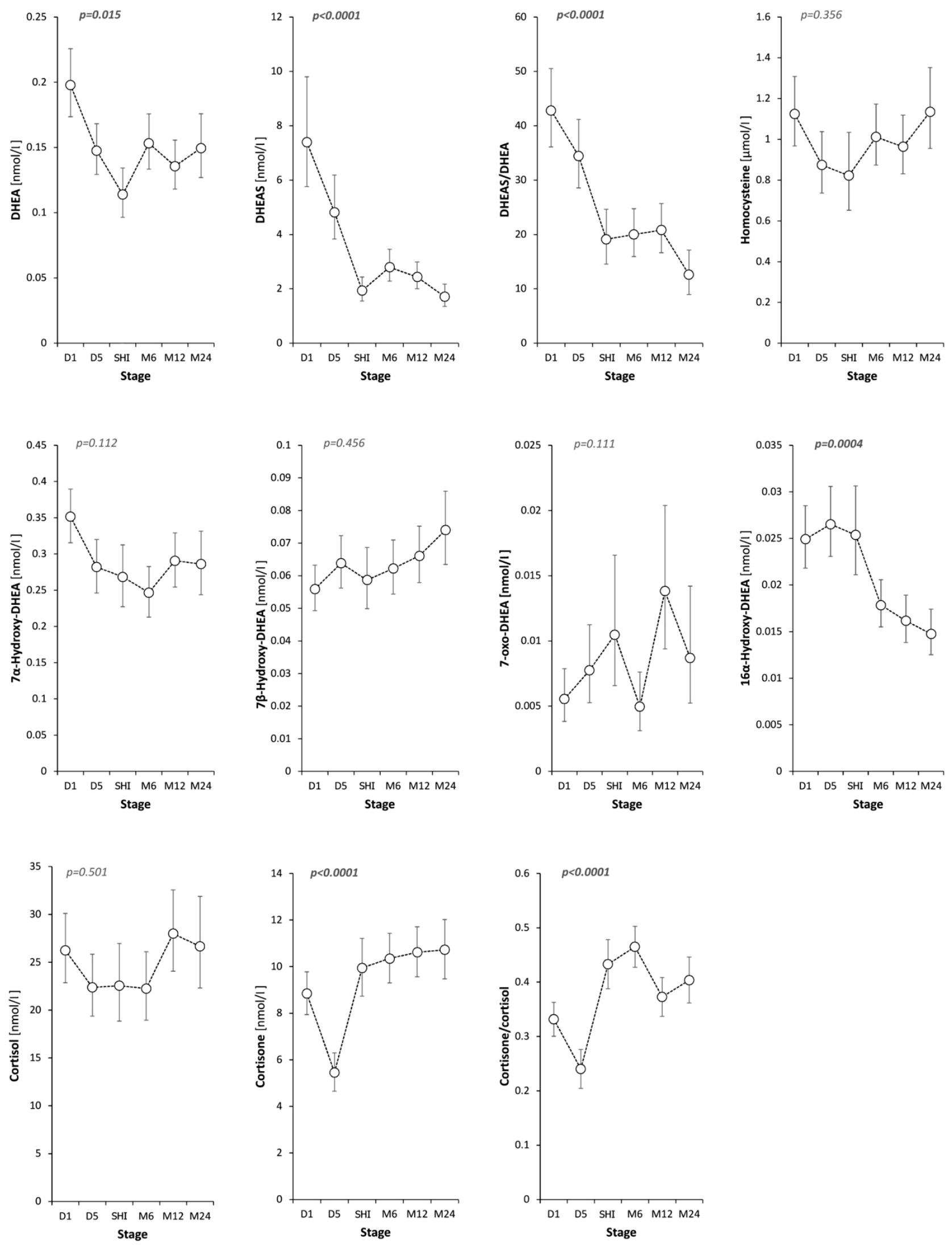

Fig. 1. Cerebrospinal fluid levels of steroids and homocysteine in patients with normal pressure hydrocephalus (NPH). The figure shows the data within lumbar drainage test, shunt insertion (SHI) and 2 years after SHI. D1 and D5 indicate first and fifth day of lumbar drainage test, M6, M12 and M24 mean 6, 12 and 24 months after the shunt implantation. The statistical significances between stages are indicated above each graph. 

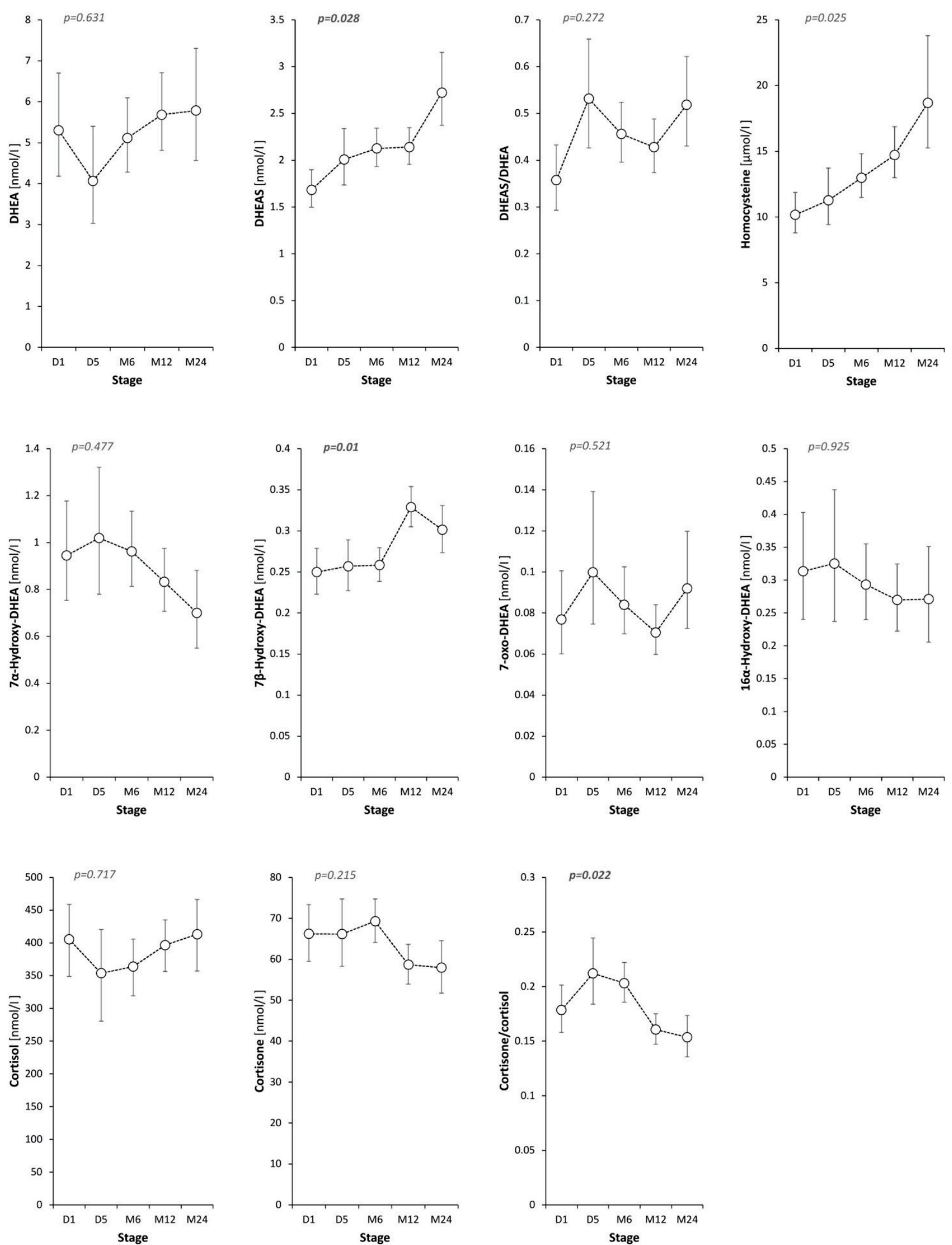

Fig. 2. Plasma levels of steroids and homocysteine in patients with normal pressure hydrocephalus (NPH). The figure shows the data within lumbar drainage test, and 2 years after shunt insertion (SHI). D1 and D5 indicate first and fifth day of lumbar drainage test, M6, M12 and M24 mean 6, 12 and 24 months after SHI. The statistical significances between stages are indicated above each graph. 
DHEA metabolism includes the formation of 7-oxygenated metabolites and 16 $\alpha$-hydroxy-DHEA. It is assumed that 16 $\alpha$-hydroxy-DHEA may cause the opposite effects to the immunoprotective 7-oxygenated ones. The increased levels of 16 $\alpha$-hydroxy-DHEA are associated with autoimmune and brain disorders (Pouzar et al. 2005), however its physiological role is still not fully understood. The significant decrease of CSF $16 \alpha$-hydroxy-DHEA after SHI, which was even present 2 years after SHI, is in accordance with previously reported findings (Morfin and Starka 2001). CSF $16 \alpha$-hydroxy-DHEA may be useful analyte biomarker in shunted NPH patient's follow-up. Concerning CSF 7-oxygenated DHEA metabolites, not one of the ANOVA models was significant. In plasma, $7 \beta$-hydroxy-DHEA was increased within 1 year of the SHI. No other 7-oxygenated plasma metabolites were changed. $7 \beta$-hydroxy-DHEA is the final product in the HSD11B1 metabolic pathway (Muller et al. 2006). The accumulation of 7 $\beta$-hydroxy-DHEA in CSF of NPH patients with an implanted shunt indicated the successful SHI effect.

The transformation of 7-oxygenated DHEA metabolites is catalyzed by HSD11B1, which is also connected with the cortisol and cortisone interconversion. Cortisol and its depot form cortisone are of peripheral origin. Approximately one tenth of these circulated steroids cross $\mathrm{BBB}$ and remain in the CSF (Guazzo et al. 1996, Beran et al. 2011). Both can be also interconverted directly in the brain by HSD11B1 (Holmes and Seckl 2006). Elevated CSF cortisol levels are suggested to be harmful in several neurodegenerative disorders (Popp et al. 2015, Sosvorová et al. 2012). Taking into account the cortisol mineralocorticoid activity, its CSF levels may be possible indicator in the follow up of NPH subjects. The inactivation of cortisol by its transformation to biologically inactive cortisone may be a protective factor avoiding neurodegenerative disease progression. The decrease of CSF cortisone as well as the CSF cortisone/cortisol ratio observed in our study during the LD may be the response to the stressful LD process. After SHI, the CSF cortisone levels increased and remained stable within the whole observation period. The same was observed in the CSF cortisone/cortisol ratio, except for the 1 year period, when this ratio decreased. The increase of cortisone correlates well with the maintenance of patient's improvement after SHI. In contrast to CSF, the cortisone/cortisol plasma levels decreased between 6 and 12 months after SHI and remain decreased within 2 years.
This decrease showed the relative increase of plasma cortisol which may reflect the slow progression of the general degenerative changes, which are common in the elderly.

An independent indicator directly related to the neurodegenerative diseases is homocysteine. Increased plasma and CSF levels of this amino acid were observed in various neurodegenerative disorders including NPH (Seshadri et al. 2002, Bičíková et al. 2004, Isobe et al. 2005, Sosvorova et al. 2014). As previously published, CSF homocysteine levels could serve as an indicator supporting the neurosurgeon's decision for SHI (Sosvorova et al. 2014). In this study, CSF homocysteine levels did not change in shunt-treated NPH patients during the observed period. Contrary to CSF levels, important changes were discovered in plasma levels of homocysteine. The continuous increase of plasma homocystein levels intensified after 1 year of the SHI. These reflect the progression of neurodegenerative changes. Plasma homocysteine may serve as an important diagnostic tool in the observation of disease progression in shunt-treated NPH patients as in other neurodegenerative diseases. An increased plasma homocysteine may be associated with the onset of NPH-related dementia progression. In our study, no one patient showed the visible NPH-related dementia changes, which according to some recent studies usually appears approximately 5 years from SHI (Koivisto et al. 2013). It may be of interest to further observe this group of patients for at least 5 years and compare plasma homocysteine levels as well as other measured analytes in those where NPH-related dementia develops to those where it does not.

\section{Conclusion}

Our findings suggest that the assessment of estimated analytes in this clinical study may help in the understanding of the pathophysiology and treatment of NPH. A limitation of our trial was the sample size of it.

The most pronounced changes in CSF during the 2-years period were found in the levels of DHEAS, DHEA and 16 $\alpha$-hydroxy-DHEA. In plasma, the significantly altered levels of DHEAS, 7 $\beta$-hydroxyDHEA and homocysteine were found. All significantly altered neurosteroids may be indicators in the disease progression and monitoring the effectiveness of SHI. Moreover, plasma homocysteine may serve as an early indicator of NPH-related dementia. 


\section{Conflict of Interest}

There is no conflict of interest.

\section{Acknowledgements}

This work was supported by grant No. NT12349-4 of the Internal Grant Agency of the Czech Ministry of Health.

\section{References}

BERAN O, DZUPOVA O, HOLUB M: Cortisol kinetics in cerebrospinal fluid during bacterial meningitis. $J$ Clin Neurosci 18: 1001-1002, 2011.

BERGSNEIDER M, BLACK PM, KLINGE P, MARMAROU A, RELKIN N: Surgical management of idiopathic normal-pressure hydrocephalus. Neurosurgery 57: S29-S39; discussion ii-v, 2005.

BIČÍKOVÁ M, Ř́POVÁ D, HILL M, JIRÁK R, HAVLÍKOVÁ H, TALLOVÁ J, HAMPL R: Plasma levels of 7-hydroxylated dehydroepiandrosterone (DHEA) metabolites and selected amino-thiols as discriminatory tools of Alzheimer's disease and vascular dementia. Clin Chem Lab Med 42: 518-524, 2004.

BROWN RC, HAN Z, CASCIO C, PAPADOPOULOS V: Oxidative stress-mediated DHEA formation in Alzheimer's disease pathology. Neurobiol Aging 24: 57-65, 2003.

CORPECHOT C, ROBEL P, AXELSON M, SJOVALL J, BAULIEU EE: Characterization and measurement of dehydroepiandrosterone sulfate in rat brain. Proc Natl Acad Sci USA 78: 4704-4707, 1981.

EL KIHEL L: Oxidative metabolism of dehydroepiandrosterone (DHEA) and biologically active oxygenated metabolites of DHEA and epiandrosterone (EpiA)-recent reports. Steroids 77: 10-26, 2012.

FERROUD C, REVIAL G, MORFIN R: Chemical and biochemical approaches to the production of 7-hydroxylated C19-steroids. Horm Mol Biol Clin Invest 10: 293-299, 2012.

FORNER GINER J, SANZ-REQUENA R, FLOREZ N, ALBERICH-BAYARRI A, GARCIA-MARTI G, PONZ A, MARTI-BONMATI L: Quantitative phase-contrast MRI study of cerebrospinal fluid flow: a method for identifying patients with normal-pressure hydrocephalus. Neurologia 29: 68-75, 2014.

GIATTI S, GARCIA-SEGURA LM, MELCANGI RC: New steps forward in the neuroactive steroid field. $J$ Steroid Biochem Mol Biol 153: 127-134, 2015.

GUAZZO EP, KIRKPATRICK PJ, GOODYER IM, SHIERS HM, HERBERT J: Cortisol, dehydroepiandrosterone (DHEA), and DHEA sulfate in the cerebrospinal fluid of man: relation to blood levels and the effects of age. J Clin Endocrinol Metab 81: 3951-3960, 1996.

HAMPL R, HILL M, STÁRKA L: DHEA metabolites during the life span. In: DHEA and the Brain. MORFIN R (ed), Taylor \& Francis, London and New York, 2003.

HOLMES MC, SECKL JR: The role of 11beta-hydroxysteroid dehydrogenases in the brain. Mol Cell Endocrinol 248: 9-14, 2006.

HUŠEK P, MATUCHA P, VRÁNKOVÁ A, ŠIMEK P: Simple plasma work-up for a fast chromatographic analysis of homocysteine, cysteine, methionine and aromatic amino acids. J Chromatography B 789: 311-322, 2003.

ISOBE C, MURATA T, SATO C, TERAYAMA Y: Increase of total homocysteine concentration in cerebrospinal fluid in patients with Alzheimer's disease and Parkinson's disease. Life Sci 77: 1836-1843, 2005.

JARAJ D, RABIEI K, MARLOW T, JENSEN C, SKOOG I, WIKKELSO C: Prevalence of idiopathic normal-pressure hydrocephalus. Neurology 82: 1449-1454, 2014.

KANCHEVA R, HILL M, NOVAK Z, CHRASTINA J, VELIKOVA M, KANCHEVA L, RIHA I, STARKA L: Peripheral neuroactive steroids may be as good as the steroids in the cerebrospinal fluid for the diagnostics of CNS disturbances. J Steroid Biochem Mol Biol 119: 35-44, 2010.

KAZUI H, MORI E, OHKAWA S, OKADA T, KONDO T, SAKAKIBARA R, UEKI O, NISHIO Y, ISHII K, KAWAGUCHI T, ISHIKAWA M, TAKEDA M: Predictors of the disappearance of triad symptoms in patients with idiopathic normal pressure hydrocephalus after shunt surgery. J Neurol Sci 328: 64-69, 2013.

KIM SB, HILL M, KWAK YT, HAMPL R, JO DH, MORFIN R: Neurosteroids: cerebrospinal fluid levels for Alzheimer's disease and vascular dementia diagnostics. J Clin Endocrinol Metab 88: 5199-5206, 2003.

KLINGE P, HELLSTROM P, TANS J, WIKKELSO C: One-year outcome in the European multicentre study on iNPH. Acta Neurol Scand 126: 145-153, 2012. 
KOIVISTO AM, ALAFUZOFF I, SAVOLAINEN S, SUTELA A, RUMMUKAINEN J, KURKI M, JÄÄSKELÄINEN JE, SOININEN H, RINNE J, LEINONEN V: Poor cognitive outcome in shunt-responsive idiopathic normal pressure hydrocephalus. Neurosurgery 72: 1-8, 2013.

LEENEN FH: The central role of the brain aldosterone-"ouabain" pathway in salt-sensitive hypertension. Biochim Biophys Acta 1802: 1132-1139, 2010.

LUCHETTI S, BOSSERS K, VAN DE BILT S, AGRAPART V, MORALES RR, FRAJESE GV, SWAAB DF: Neurosteroid biosynthetic pathways changes in prefrontal cortex in Alzheimer's disease. Neurobiol Aging 32: 1964-1976, 2011.

MELLON SH: DHEA and brain development. In: DHEA and the Brain. MORFIN R (ed), Taylor \& Francis, London and New York, 2003.

MORFIN R, STARKA L: Neurosteroid 7-hydroxylation products in the brain. Int Rev Neurobiol 46: 79-95, 2001.

MULLER C, POMPON D, URBAN P, MORFIN R: Inter-conversion of 7alpha- and 7beta-hydroxydehydroepiandrosterone by the human 11beta-hydroxysteroid dehydrogenase type 1. J Steroid Biochem Mol Biol 99: 215-222, 2006.

NAYLOR JC, HULETTE CM, STEFFENS DC, SHAMPINE LJ, ERVIN JF, PAYNE VM, MASSING MW, KILTS JD, STRAUSS JL, CALHOUN PS, CALNAIDO RP, BLAZER DG, LIEBERMAN JA, MADISON RD, MARX CE: Cerebrospinal fluid dehydroepiandrosterone levels are correlated with brain dehydroepiandrosterone levels, elevated in Alzheimer's disease, and related to neuropathological disease stage. J Clin Endocrinol Metab 93: 3173-3178, 2008.

NIGIM F, CRITCHLOW JF, SCHNEIDER BE, CHEN C, KASPER EM: Shunting for hydrocephalus: analysis of techniques and failure patterns. $J$ Surg Res 191: 140-147, 2014.

POCA MA, SOLANA E, MARTINEZ-RICARTE FR, ROMERO M, GANDARA D, SAHUQUILLO J: Idiopathic normal pressure hydrocephalus: results of a prospective cohort of 236 shunted patients. Acta Neurochir Suppl 114: 247-253, 2012.

POPP J, WOLFSGRUBER S, HEUSER I, PETERS O, HULL M, SCHRODER J, MOLLER HJ, LEWCZUK P, SCHNEIDER A, JAHN H, LUCKHAUS C, PERNECZKY R, FROLICH L, WAGNER M, MAIER W, WILTFANG J, KORNHUBER J, JESSEN F: Cerebrospinal fluid cortisol and clinical disease progression in MCI and dementia of Alzheimer's type. Neurobiol Aging 36: 601-607, 2015.

POUZAR V, ČERNÝ I, HILL M, BIČÍKOVÁ M, HAMPL R: Derivatives of 16 $\alpha$-hydroxy-dehydroepiandrosterone with an additional 7-oxo or 7-hydroxy substituent: synthesis and gas chromatography/mass spectrometry analysis. Steroids 70: 739-749, 2005.

REDDY GK, BOLLAM P, CALDITO G: Long-term outcomes of ventriculoperitoneal shunt surgery in patients with hydrocephalus. World Neurosurg 81: 404-410, 2014.

RELKIN N, MARMAROU A, KLINGE P, BERGSNEIDER M, BLACK PM: Diagnosing idiopathic normal-pressure hydrocephalus. Neurosurgery 57: 4-16, 2005.

RIGAMONTI D: Adult Hydrocephalus. Cambridge University Press, New York, 2014.

ROBINZON B, MICHAEL KK, RIPP SL, WINTERS SJ, PROUGH RA: Glucocorticoids inhibit interconversion of 7-hydroxy and 7-oxo metabolites of dehydroepiandrosterone: a role for 11beta-hydroxysteroid dehydrogenases? Arch Biochem Biophys 412: 251-258, 2003.

SECKL JR, WALKER BR: 11 beta-hydroxysteroid dehydrogenase type 1 as a modulator of glucocorticoid action: from metabolism to memory. Trends Endocrin Med 15: 418-424, 2004.

SESHADRI S, BEISER A, SELHUB J, JACQUES PF, ROSENBERG IH, D'AGOSTINO RB, WILSON PW, WOLF PA: Plasma homocysteine as a risk factor for dementia and Alzheimer's disease. New Engl J Med 346: 476-483, 2002.

SINCLAIR AJ, WALKER EA, BURDON MA, VAN BEEK AP, KEMA IP, HUGHES BA, MURRAY PI, NIGHTINGALE PG, STEWART PM, RAUZ S, TOMLINSON JW: Cerebrospinal fluid corticosteroid levels and cortisol metabolism in patients with idiopathic intracranial hypertension: a link between 11beta-HSD1 and intracranial pressure regulation? J Clin Endocrinol Metab 95: 5348-5356, 2010. 
SOSVOROVA L, BESTAK J, BICIKOVA M, MOHAPL M, HILL M, KUBATOVA J, HAMPL R: Determination of homocysteine in cerebrospinal fluid as an indicator for surgery treatment in patients with hydrocephalus. Physiol Res 63: 521-527, 2014.

SOSVOROVÁ L, BIČÍKOVÁ M, MOHAPL M, HAMPL R: Steroids and their metabolites in CSF from shunt as potential predictors of further disease progression in patients with hydrocephalus and the importance of 11ß-hydroxysteroid dehydrogenase. Horm Mol Biol Clin Invest 10: 287-292, 2012.

SOSVOROVA L, HILL M, MOHAPL M, VITKU J, HAMPL R: Steroid hormones in prediction of normal pressure hydrocephalus. J Steroid Biochem Mol Biol 152: 124-132, $2015 \mathrm{a}$.

SOSVOROVA L, VITKU J, CHLUPACOVA T, MOHAPL M, HAMPL R: Determination of seven selected neuro- and immunomodulatory steroids in human cerebrospinal fluid and plasma using LC-MS/MS. Steroids 98: 1-8, $2015 b$

STÁRKA L, DUŠKOVÁ M, HILL M: Dehydroepiandrosterone: a neuroactive steroid. J Steroid Biochem Mol Biol 145: 254-260, 2014.

VITKU J, STARKA L, BICIKOVA M, HILL M, HERACEK J, SOSVOROVA L, HAMPL R: Endocrine disruptors and other inhibitors of 11beta-hydroxysteroid dehydrogenase 1 and 2: tissue-specific consequences of enzyme inhibition. J Steroid Biochem Mol Biol in press 2014.

WALCHENBACH R, GEIGER E, THOMEER RTWM, VANNESTE JAL: The value of temporary external lumbar CSF drainage in predicting the outcome of shunting on normal pressure hydrocephalus. J Neurol Neurosurg Psychiatry 72: 503-506, 2002.

WOJTAL K, TROJNAR MK, CZUCZWAR SJ: Endogenous neuroprotective factors: neurosteroids. Pharmacol Rep 58: $335-340,2006$. 